\title{
О подходах к оценке собственником компании инвестиционной эффективности его персональной деятельности по управлению бизнесом
}

\author{
Королев В. ${ }^{14}$, Мамонтов Д. ${ }^{15}$
}

Данная статья посвящена решению проблемь оценки эффективности деятельности собственников бизнеса.

Модели, разработанные в рамках статьи, включают показатель эффективности, который впервые рассматривается в качестве базового индикатора для принятия собственником решения о формате своего участия в управлении компанией и зависит не только от измеримых денежных инвестиций, но также от инвестиций личного времени собственника в бизнес.

При рассмотрении моделей также приводится раџиональное объяснение принятия собственниками решения об отходе от текущего управления компанией, что часто наблюдается на практике.

Особое внимание уделено разграничению трех базовых функиий собственников компании: предпринимательской деятельности, операчионной деятельности и контроля над менеджментом.

\section{$J E L: C 2, C 3$}

Ключевые слова: корпоративное управление, взаимоотночения владельцев и менеджмента, роль владельца в управлении бизнесом, наследование бизнеса, эффективность собственника, инвестиции личного времени

Выражаю благодарность председателю совета директоров Объединенной металлургической компании Анатолию Михайловичу Седых за дискуссию, состоявшуюся еще летом 2006 года. Она натолкнула меня на мысли, которые легли в основу этой статьи.

В. Королев

\section{Введение}

Начнем с нескольких простых вопросов.

1. Ограничивается ли вклад основателя бизнеса в его капитал только имущественной и денежной формой?

Многие основатели бизнеса, начинавшие с нуля, скажут, что нет, поскольку помимо этих форм вклада основатель инвестирует еще и свое время.

2. Можно ли оценить этот временной вклад? Сколько стоит время собственника бизнеса?

Казалось бы, можно попробовать оценить его по аналогии с оценкой стоимости времени топ-менеджеров. Рынок трудовых ресурсов позволяет получить такие оценки. Однако аналогия здесь неуместна, поскольку собственник не нанимается в свой бизнес в качестве собственника. Нет рынка труда собственников-бизнесменов.

3. Здесь возникает третий вопрос: на основе каких подходов можно оценивать

\footnotetext{
${ }^{14}$ Президент ООО «Центр корпоративного развития» (www.ncda.ru); президент Некоммерческого партнерства «Северо-Западный центр корпоративного управления» (www.nwcgc.ru); член Ассоциации независимых директоров (www.nand.ru).

15 Консультант ООО «Центр корпоративного развития»; стажер-исследователь НИУ ВШЭ, факультет «Менеджмент», специальность «Управление проектами».
} 
стоимость времени, посвященного управлению бизнесом его собственником?

Позиция авторов следующая: поскольку существуют методы оценки имущественных вкладов, значит, должны существовать методы оценки временного вклада. Эта статья посвящена обсуждению подходов к разработке таких методов оценки, поскольку без оценки стоимости этого вклада невозможно оценить эффективность деятельности владельца компании, направленной на управление принадлежащим ему бизнесом ${ }^{16}$.

Соответственно, целью данной работы является построение модели оценки эффективности собственника как предпринимателя и как капиталиста, которая позволит оценить динамику его эффективности в определенный временной период, а также целесообразность и выгоду его участия в управлении компанией.

Для достижения данной цели необходимо решить ряд задач:

1. Сформулировать проблему, а также описать историю ее возникновения.

2. Определить основные термины и понятия, необходимые для формулирования предпосылок модели и непосредственно для построения самой модели.

3. Описать финансово-экономическую модель оценки эффективности собственника во времени и ее предпосылки, а также охарактеризовать процедуру ее применения и способы интерпретации показателей модели.

4. Построить дополнительную модель, связывающую показатель эффективности собственника и оптимальный рост стоимости компании во времени.

Объектом исследования являются в первую очередь 100\%-ные владельцы компаний, принимающие основные решения относительно характера и стратегии их функционирования и развития, т.е. собственники. Предметом изучения является эффективность деятельности собственников, оценке которой и посвящена данная работа.

Эффективность деятельности собственника и эффективность компании непосредственно влияют на характер развития компании на рынке и степень ее конкурентоспособности, а также на возможность оптимизации распределения временных ресурсов собственника с целью их наиболее выгодного использования. Время - это один из наиболее ценных активов для любого экономического агента. В связи с этим оптимизация его использования является ключевым аспектом деятельности как для самих собственников, так и для их компаний. Принимая во внимание этот фактор, можно утверждать, что тема данной работы не только актуальна для нашего времени, но также имеет широкий спектр перспектив развития, поскольку предлагаемая модель может применяться и модифицироваться при решении вопросов оценки эффективности деятельности различных агентов и отношений между ними.

\section{1. История появления, развития и формализация проблемы}

От кого в первую очередь зависит судьба частного бизнеса? На ком лежит ответственность за выбор того направления, которого будет придерживаться компания в процессе своего развития? Если рассматривать малый и средний бизнес, в частности непубличные компании, еще не вышедшие на IPO, то основными лицами, принимающими наиболее важные стратегические решения, являются их собственники (совладельцы - в случае партнерского владения). В рамках настоящей статьи, если не указано иное, мы для простоты рассуждений будем считать владение 100\%-ным. Соответственно, собственник распределяет свое рабочее время на три основных направления: предпринимательская деятельность; контроль за деятельностью исполнительного менеджмента исходя из своей роли капиталиста; и операционная деятельность (текущее управление компанией) (Материалы и презентации...).

В рамках выполнения предпринимательских функций собственник занимается становлением, выращиванием и развитием компании, принятием стратегических решений,

\footnotetext{
${ }^{16}$ В рамках статьи для упрощения мы не различаем понятия «бизнес» и «компания», хотя в реальности они часто не являются синонимами.
} 
реализацией и донесением до менеджмента своего видения образа компании в долгосрочной перспективе. Также в качестве предпринимательской функции можно выделить формирование и организацию других бизнесов и компаний, но это будут уже альтернативные по отношению к данному бизнесу инвестиции времени.

Функция контроля подразумевает соотнесение поставленных собственником целей и достигнутых менеджерами результатов. Фактически это стратегический контроль над менеджментом, не подразумевающий непосредственного вмешательства в операционную деятельность. Обычно такой контроль осуществляется в рамках деятельности совета директоров.

Помимо этого, собственник может взять (и на практике часто берет) на себя часть ключевых функций операционного управления. Это может быть связано с рядом причин: фактическая необходимость вмешательства собственника в деятельность менеджмента, нехватка кадров и квалифицированного менеджмента, боязнь владельца не уследить за всеми операциями внутри компании и в связи с этим принять неверные решения, а также многими другими. В период стартапа, когда собственный капитал компании невелик, каждая сделка среднего объема представляет относительно большой риск для компании, поэтому каждую такую сделку можно считать стратегической. В этот период владелец предпочитает управлять такими значимыми рисками.

Таким образом, собственник может выполнять несколько функций. На ранних этапах развития компании ему хватает времени на выполнение всех своих функций, в связи с относительно небольшим масштабом бизнеса. С ростом и развитием компании ее владелец сталкивается с недостатком ключевого ресурса - личного времени. Ему приходится делегировать свои полномочия исполнительному органу, формировать совет директоров для контроля и стратегического управления и постепенно отходить от операционного управления в сторону стратегического (Корпоративное управление, 2007). С учетом вышеперечисленных обстоятельств возникает ряд вопросов и проблем:

1. Как наиболее точно определить момент, когда необходимо делегировать часть полномочий собственника исполнительному органу и совету директоров? Когда следует озаботиться вопросом формирования эффективной системы корпоративного управления? (Пособие... 2004)

2. Компании часто сталкиваются с проблемой «преждевременного старения» (Адизес, 2008), когда владелец концентрирует усилия на операционной деятельности. Соответственно у компании пропадает орган стратегического развития, а также появляются проблемы в операционном менеджменте из-за нехваткипрофессиональных высококвалифицированных менеджеров в команде руководителей.

3. Собственник концентрируется на развитии и контроле уже существующей компании, имея потенциал создания новых бизнесов и проектов. Таким образом, у него пропадает предпринимательская функция. Это существенно снижает потенциал развития экономики, который так важен для социально-экономического прогресса (Понятковский, 2011).

4. В связи с тем что весь бизнес держится на одном собственнике или нескольких совладельцах, становятся проблематичными его продажа или передача по наследству без потери рыночной стоимости или эффективности функционирования (Кросби, 2004).

Актуальность данной проблемы заключается в том, что владелец выбирает свою управленческую позицию и принимает соответствующие решения о характере работы в собственной компании с учетом прямых и косвенных экономических, финансовых или социальных критериев, как внутренних, так и внешних. Однако в связи с обилием факторов и переменных, динамичной окружающей бизнес-средой или неверной оценкой перспектив компании собственник часто принимает не самые рациональные решения.

\section{2. Моделирование оценки эффективности собственника компании}

В научных статьях и журналах довольно часто фигурирует такое понятие, как 
«эффективный собственник». Более того, существует несколько различных мнений по поводу интерпретации данного термина. Одним из наиболее распространенных и общепризнанных является определение, впервые сформулированное в эпоху приватизации: эффективный собственник - это владелец эффективной компании (Гайдар, 2009). Другими словами, если компания эффективно функционирует на рынке, то и ее собственник эффективен, поскольку именно он является «субъектом хотения» (Королев, 2004) т.е. субъектом, управляющим бизнесом в своих интересах. Однако в рамках данной работы термин «эффективный собственник» будет интерпретироваться с иной точки зрения.

В первую очередь необходимо понять, что в принципе означает термин «эффективность». Эффективность в нашем понимании - это относительный показатель, в числителе которого стоит результат, а в знаменателе - затраты (Рыбаков, 2011). В качестве эффективности можно рассматривать отношение доходов к расходам, прибыли - к затратам и т.д.

Итак, эффективность - относительный эффект операции, проекта, определяемый как отношение эффекта, результата к затратам, расходам, обусловившим, обеспечившим его получение (Современный экономический словарь).

В связи с наличием у собственника выбора между двумя стратегиями (быть пассивным совладельцем, который практически не участвует в деятельности компании, или управлять своей компанией, осуществляя предпринимательскую функцию), а также в рамках определения термина «эффективность» следует заключить, что его эффективность определяется отношением дополнительного прироста стоимости компании, полученного благодаря работе ее владельца, и затрат его личного времени на управление компанией.

Мы исходим из того, что эффективная компания не делает автоматически собственника эффективным (Королев, 2004). Например, собственник, работающий в эффективной компании и привносящий относительно небольшой дополнительный прирост ее стоимости по сравнению с количеством затрат собственного времени и ресурсов, не будет считаться эффективным. Оптимальное решение для него - это делегирование своих полномочий наемному исполнительному органу управления. В этом случае владелец может потерять небольшой прирост стоимости, обеспечиваемый его личным участием в управлении, но при этом существенно снизит затраты своего времени и ресурсов. Исходя из данного предположения, разрабатываемая модель предназначена для оценки персональной эффективности собственника, который принимает решение только о том, следует ли ему инвестировать свое время в данный бизнес. Данный подход исключает вопросы оценки эффективности деятельности владельцев компаний по управлению их бизнесом с точки зрения потенциальных новых собственников (для случаев M\&A, прямых и портфельных инвестиций).

Характер деятельности владельца компании как предпринимателя заключается в том, что он не просто от лица фирмы управляет денежным капиталом, который инвестировал в бизнес, но также тратит определенное количество времени на осуществление данного процесса. Собственник - интегратор, который работает в компании в течение некоторого времени и старается организовать команду сотрудников, менеджеров с целью добиться определенной синергии от их деятельности и таким образом развивать компанию (Российская корпорация... 2008).

Основным назначением модели, разрабатываемой в этой работе, является определение динамики эффективности деятельности собственника во времени. Результаты, получаемые при использовании данной модели, призваны служить для владельца индикатором того, что его предпринимательская эффективность начинает снижаться и ему необходимо озаботиться вопросами преемственности, формирования совета директоров и делегирования всех или части своих полномочий новому органу управления (Королев, 2011). 


\section{1. Модель 1: стоимостная оценка работы собственника}

Экономическая теория допускает, что время работы и усилия любого экономического агента имеют определенную стоимость, т.е. могут быть оценены. Эта оценка выражается в вознаграждении агенту за выполнение определенной работы за некоторый промежуток времени. Чаще всего это зарплата, являющаяся фиксированной величиной. Следовательно, можно совершенно точно определить стоимость часа данного работника или диапазон этой стоимости, в случае если вознаграждение зависит от результатов деятельности.

Совершенно по-другому оценивается работа собственника. Дело в том, что, согласно агентской теории, он является скорее не агентом, а принципалом (Королев, 2004). Однако если владелец не пассивный, а активный, т.е. выполняет предпринимательские функции, то корректно говорить о стоимости его времени. Его «заработной платой» фактически является прирост стоимости компании ${ }^{17}$. Собственник стремится развивать компанию, повышать ее стоимость и генерировать доходы. Более того, чем выше будет прирост капитализации компании, чем крупнее она становится, тем выше окажется стоимость часа его работы (при условии, что он тратит на компанию одинаковое количество личного времени в течение различных сравниваемых периодов). При этом данные факторы зависят не только от усилий самого владельца, но и от качества и результативности работы всей системы в целом, т.е. менеджеров, экономистов, финансистов, бухгалтеров, производственных работников и даже уборщиц. Практически не представляется возможным выделить составляющую вклада собственника в общий доход компании, или, другими словами, трудно выделить те денежные потоки, которые генерирует он сам. Тем не менее без данного показателя не будет возможности измерить его индивидуальную эффективность как предпринимателя.

В связи с этим определяется ключевая предпосылка модели: разница между фактическим ростом компании за период и среднерыночным темпом роста компаний в данной отрасли является результатом работы (трудового вклада) собственника компании.

Если он не участвует в деятельности компании (является пассивным агентом), то в условиях эффективной системы корпоративного управления и профессионализма менеджмента компания сможет расти среднеотраслевыми темпами. Однако в таком случае прирост сверх рыночного уровня следует объяснять лишь решениями и действиями самого собственника, обладающего чутьем, «нюхом», своеобразным видением и пониманием бизнеса. Равно как и более низкие темпы прироста, нежели рыночные, следует также списать на вмешательство владельца.

Таким образом, существует два вида доходности:

1. $R n-$ фактический прирост стоимости компании за определенный период.

2. $R e$ - среднерыночный прирост стоимости с учетом специфики данного предприятия в отрасли.

Их разницей, $R n-R e=d R$, будет тот дополнительный прирост стоимости, который является результатом работы собственника компании.

Информацию о существующей ставке $R e$ компания всегда может узнать или оценить. Прежде всего такая информация доступна для компаний благодаря открытым и закрытым данным, отражающим деятельность компаний в отрасли. Другим возможным способом может быть оценка $R e$ с помощью аналога модели CAРМ (Википедия):

(1)

$$
\mathrm{Re}=R f+\beta *(R m-R f),
$$

Где:

$R e$ - ожидаемая отдача на инвестиции (прирост стоимости компании);

\footnotetext{
${ }^{17}$ Если собственник владеет менее $100 \%$ капитала, то инвестиционной стоимостью затраченного им времени будет дополнительная прибыль компании, а его «зарплатой» - доля прибыли, соответствующая его доле в управлении. Поэтому при размывании пакета собственника снижается экономическая привлекательность для него управленческой деятельности в качестве владельца. Но анализ такого сценария не является целью данной статьи.
} 
$R f$ - безрисковая отдача на инвестиции;

$R m$ - ожидаемая рыночная отдача на инвестиции;

$\beta$ - коэффициент чувствительности инвестиций на ставку $R m$.

Эффективность измеряется как отношение доходов к затратам. Дополнительный прирост стоимости компании, генерируемый благодаря работе собственника, определен выше в качестве ставки $d R$. Не менее важным показателем являются затраты собственника ${ }^{18}$. Они будут состоять из двух частей - материальной и нематериальной.

Материальная часть затрат $(K)$ - это фактические инвестиции реального капитала (чаще всего денежного или имущественного).

Нематериальная часть затрат - это то время владельца, которое он тратит за период с целью обеспечить компании дополнительный прирост $d R$. Данный вид затрат также необходимо измерить. Однако, в соответствии с предположениями модели, это возможно сделать лишь де-факто, то есть когда уже известны доходы собственника за период.

Таким образом, базовое выражение модели может быть записано следующим образом:

$$
(K+S) *(1+\mathrm{Re})=K *(1+\mathrm{Re}+d R) .
$$

В данном случае параметр $S$ отражает стоимостную оценку всего времени собственника, которое он потратил на бизнес за период $t$. Предположим, что собственник оценивает свое время ( $N$ часов в год) в размере $S$ руб. Итак, он вложил $K$ руб. деньгами и $S$ руб. временем (часами). Предположим для простоты, что временной капитал инвестируется одновременно с денежным, т.е. начальный капитал равен $(K+S)^{19}$. После осуществления этих вложений владельца можно рассматривать как пассивного инвестора, завершившего инвестиции. В таком случае у него нет никаких оснований ожидать отдачи от этого суммарного капитала больше, чем $R e$. Эта задача может интерпретироваться как обычное задание менеджменту: сделать так, чтобы по итогам периода компания стоила $(K+d K)=(K$ $+S) *(1+R e)=K *(1+R e+d R)$, где $d K-$ это прирост капитала за счет инвестиций суммарного капитала. Поскольку целевое значение $S$ было определено в начале периода, то можно соответственно получить $d K$ или $d R$.

Можно поставить вопрос иначе: каким образом собственник может получить отдачу на свой капитал $(K)$ не в размере $R e$, а $(R e+d R)$ ? В этом случае ему необходимо определить, какое личное время он готов потратить для превышения среднерыночных темпов роста компаний. Если после затрат в $N$ часов его цель достигнута, т.е. компания стоит $K *(1+R e$ $+d R)$, он может оценить эквивалент денежного капитала, которым было его время, затраченное на работу в компании. Поскольку известны все параметры, кроме $S$, то стоимостной оценкой затраченного собственником времени будет:

$$
S=\frac{K^{*} d R}{1+\mathrm{Re}}
$$

Из данного уравнения видно, что стоимость времени собственника пропорциональна как его начальному капиталу, так и приросту $d R$, по сравнению с рыночным уровнем, который (прирост) достигается благодаря его (собственника) участию в управлении. С другой стороны стоимость времени владельца уменьшается при повышении среднерыночной доходности $R e$.

Наиболее простым способом оценки эффективности собственника является использование фактических показателей и результатов за предыдущие периоды. Поскольку модель служит индикатором снижения эффективности, то владельцу совершенно необязательно прогнозировать точные значения $S$ и $d R$. Благодаря данной модели, он имеет возможность видеть динамику собственной эффективности за предыдущие периоды, что и будет для него индикатором того, пришло ли время задуматься о снижении своего трудового

\footnotetext{
18 Тот объем различного рода ресурсов (денежного капитала, личного времени и т.д.), которые собственник использует для получения доходов в виде прироста стоимости компании.

${ }^{19}$ Ниже будет рассмотрен более точный вариант, учитывающий распределенный характер инвестиций времени.
} 
участия в бизнесе.

Опишем данную модель для $n$-го периода.

В любой $n$-й период времени можно оценить временной вклад собственника:

$$
S_{n}=\frac{K_{n} * d R_{n}}{1+\operatorname{Re}}
$$

где:

$K n$ - (руб.) капитал на начало $n$-го периода;

$d R n$ - разница между фактическим приростом стоимости компании за период $\mathrm{n}$ (назовем ее $R n$ ) и среднерыночным темпом роста $R e$ в период $n: d R_{n}=R_{n}-R_{e}$ (\% за период). Фактически:

$$
R_{n}=\frac{K_{n+1}}{K_{n}}-1=\frac{d K_{n}}{K_{n}}
$$

где

$$
{ }_{d} K_{n}=K_{n+1}-K_{n}
$$

это прирост капитала в течение $n$-го периода.

Подставим вместо $R n$ соответствующее выражение и получим:

$$
\begin{gathered}
d R_{n}=\frac{d K_{n}}{K_{n}}-\mathrm{Re} \\
S_{n}=K_{n} * \frac{d K_{n}}{K_{n}-\operatorname{Re}} \div(1+\operatorname{Re})=\frac{d K_{n}-K_{n} \cdot \operatorname{Re}}{1+\operatorname{Re}} .
\end{gathered}
$$

Из формулы (8) следует, что для верной оценки показателя $\mathrm{S}$ достаточно знать, насколько фактически изменился собственный капитал, а также среднерыночные темпы роста по данной отрасли ${ }^{20}$.

Рассмотрим теперь следующее немаловажное обстоятельство, связанное с фундаментальным свойством времени - его длительностью. В отличие от денежных инвестиций $K$, которые, в соответствии с допущениями модели, вкладываются в проект единовременно, инвестиции времени собственника в размере $S$ осуществляются не единовременно в начале периода, а равномерно в течение всего периода. Принятие данного предположения вызывает необходимость введения поправочного коэффициента на значение $S$ в формулах (2) и (3).

В связи с этим обстоятельством в том случае, если собственник абсолютно равномерно осуществляет инвестиции своего времени в течение периода, реальная отдача $R e$ будет примерно в два раза ниже. Соответственно прирост стоимости компании, которую получит

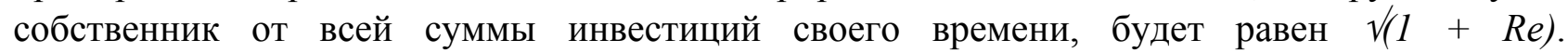
Следовательно, поправочный коэффициент на показатель $S$, который позволит собственнику получить реальный прирост $R e$, будет иметь следующий вид:

$$
A=\frac{1+\mathrm{Re}}{\sqrt{1+\mathrm{Re}}} \text { или } A=(1+\mathrm{Re})^{1 / 2} \text {. }
$$

Таким образом, формула (3) претерпит следующее изменение:

$$
S=\frac{K^{*} d R}{\sqrt{(1+\mathrm{Re}}}
$$

\footnotetext{
${ }^{20}$ В рамках настоящей статьи для упрощения не различаются понятия капитализации и собственного капитала. Считаем, что стоимость компании и собственный капитал возрастают на величину прибыли.
} 
а формула (9) примет следующий вид:

$$
S_{n}=A * K_{n} * \frac{d K_{n}}{K_{n}-\mathrm{Re}} \div(1+\mathrm{Re})=\frac{d K_{n}-K_{n} * \mathrm{Re}}{\sqrt{1+\mathrm{Re}}}
$$

Получив значение $S$, собственник имеет возможность определить, насколько эффективно он осуществляет свою деятельность, как активный владелец. Если он в каждый $n$-й период тратит на работу в компании $T n$ часов, то можно оценить стоимость часа собственника в течение этого периода: $s(n)=S n / T n$ (рублей за час личного времени). Соответственно результативностью предпринимателя будет его абсолютный вклад $S n$, а эффективностью - $s(n)$ - удельный вклад в расчете на потраченный им час. Динамика данных показателей во времени покажет собственнику, удается ли ему работать столь же эффективно, как и в предыдущие периоды.

Следует также сделать еще один вывод. Распределенный в календарном времени характер инвестирования личного времени собственника приводит к тому, что стоимость его часа в номинальном выражении должна расти с течением времени, чтобы как минимум оставаться неизменной с точки зрения приведенной стоимости. Это один из наиболее важных выводов относительно свойств личного времени как инвестиционного актива: его стоимость (номинальная) должна расти с темпом не меньшим, чем $(1+R e)$, для того чтобы приведенная стоимость инвестирования каждого часа этого времени оставалась хотя бы константой.

\section{2. Модель 2: Эффективное поведение собственника в ракурсе динамики изменения стоимости компании}

Для того чтобы более точно показать характер влияния деятельности предпринимателя на стоимость его бизнеса, а также некоторым образом привязать его уход из управления бизнесом к изменению стоимости компании путем делегирования полномочий совету директоров, необходимо смоделировать два различных пути развития организации - с собственником и без него.

Первая предпосылка: в случае, если собственник компании является ее пассивным акционером, то при эффективной системе корпоративного управления и сильной менеджерской команде он может рассчитывать на рост компании среднерыночными темпами. Таким образом, стоимость компании будет характеризоваться экспоненциальным ростом во времени:

$$
V_{n}=K_{0} *(1+\mathrm{Re})^{n}
$$

где:

$V n$ - это стоимость компании в период $n$;

Кo - первоначальные, базовые инвестиции в компанию;

$R e$ - среднерыночные темпы роста компаний по отрасли, которые, для упрощения, предполагаются неизменными в течение времени.

Если рассматривать данный сценарий не в дискретном, а в непрерывном времени, что адекватно условиям функционирования бизнеса, то экспоненциальный рост компании описывается следующим выражением:

$$
V_{n}=K_{0} * e^{\operatorname{Re}^{*} t}
$$

Несмотря на то что эмпирические данные не подтверждают бесконечного экспоненциального роста компаний, данная предпосылка может существовать по нескольким причинам.

Прежде всего, эмпирика не подтверждает данную предпосылку ввиду изменяющихся условий среды, в которой работает компания. Постоянный инновационный процесс создает и 
уничтожает целые отрасли производства и бизнеса. Тем не менее, если предположить отсутствие инновационных процессов и допустить относительно стабильные внешние условия (которые вполне соответствуют эмпирике в краткосрочном периоде), то компания действительно может расти потенциально бесконечно, до тех пор, пока растет отрасль и рынок не насытится полностью.

Кроме того, если владелец будет пассивным акционером, т.е. перейдет от деятельности по управлению компанией к управлению своим капиталом, он сможет относительно легко перебросить свой капитал внутри отрасли (или диверсифицировать владение) таким образом, чтобы капитал рос экспоненциально со среднеотраслевыми темпами, которые могут быть ниже темпов роста капитала компании, которой он сам бы управлял.

Вторая предпосылка: в случае если собственник тратит определенное время на работу в своей компании в течение каждого периода (т.е. управляет компанией, а не капиталом), то стоимость компании будет иметь динамику, описываемую логистической $S$-образной кривой (Википедия), которая будет лежать выше экспоненциальной кривой «пассивного» роста стоимости компании на определенном отрезке времени. Эта кривая моделирует жизненный цикл компании.

В непрерывном времени логистическая кривая описывается следующим выражением:

$$
V_{n}=\frac{K^{\prime *} K_{0} * e^{R_{n}{ }^{*} t}}{K^{\prime}+K_{0} *\left(e^{R_{n}{ }^{*} t}-1\right)},
$$

где:

$K^{\prime}$ - это предел стоимости компании, который может быть достигнут благодаря деятельности собственника;

Ко - первоначальные инвестиции, капитал;

$R n-$ фактический рост компании за период, описываемый суммой $R e+d R$.

Предпосылка об $S$-образной динамике стоимости компании в случае работы собственника обоснована рядом логических предположений, а также научными статьями и эмпирическими исследованиями. Предполагается, что развитие многих процессов в экономике, в том числе и на предприятиях, отражается логистической кривой, представляющей собой временную либо другую зависимость параметров объекта. $S$ образной кривой моделируется процесс резкого (скачкообразного) перехода от одного стабильного состояния к другому, процесс радикальных изменений организации, сопровождающих ее инновационную деятельность, процесс нарастания и развития кризисных явлений (Основы теории и методологии инноватики).

Рассмотрим следующий числовой пример (все цифры взяты случайным образом, но удовлетворяют предпосылкам модели):

$$
\begin{aligned}
& R e=10 \%, \\
& R n=30 \%, \\
& K o=5, \\
& K^{\prime}=20 .
\end{aligned}
$$

Удовлетворяя данным условиям, графики динамики стоимости компании по двум различным сценариям будут выглядеть следующим образом (см. рис. 1). 


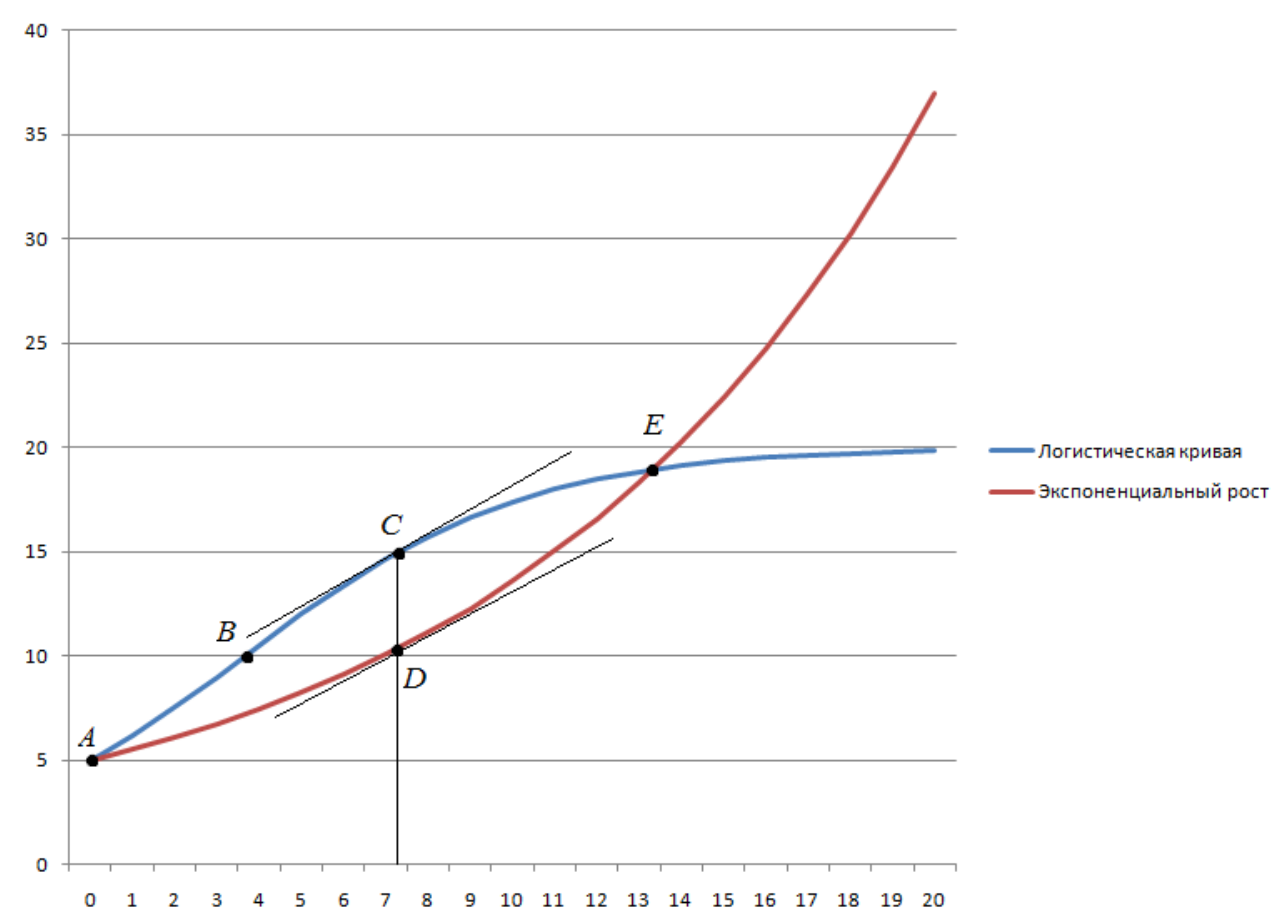

Рисунок 1. Динамика стоимости компаний с активным и пассивным собственником

По горизонтальной оси откладывается время $t$ на первые 20 периодов развития компании. По вертикальной оси - стоимость компании.

Дело в том, что, как уже упоминалось выше, собственник имеет возможность приносить дополнительный прирост стоимости компании благодаря своим предпринимательским способностям, пониманию отрасли и компании. В связи с этим логичной предпосылкой является то, что на первых этапах развития компании владелец в состоянии обеспечить более высокие темпы ее роста, чем профессиональный менеджмент, обеспечивающий среднерыночные темпы роста. Поэтому первая фаза логистической кривой $A B$ характеризует возрастающие темпы роста стоимости компании.

Однако в дальнейшем компания укрупняется, процессы становятся все более сложными и многогранными, появляется масса различных неявных взаимосвязей и побочных эффектов между различными видами деятельности. Собственнику становится все сложнее в одиночку отслеживать все процессы, происходящие в компании, при принятии решений он перестает учитывать всю специфику бизнеса, а значит, они начинают терять эффективность. Ввиду этого вторая фаза логистической кривой $B C$ описывает смену динамики возрастающих темпов роста компании в сторону снижения. Тем не менее вплоть до точки С производная логистической кривой больше производной экспоненциальной кривой, а это означает, что благодаря работе собственника компания растет темпами, которые быстрее среднерыночных.

Третья фаза логистической кривой $C E$ характеризуется снижающимися темпами роста компании. Экономическая интерпретация этого явления довольно проста - бизнес разрастается до таких размеров, когда собственник уже не в состоянии принимать решений, охватывающих и учитывающих все аспекты ведения бизнеса, ввиду их сложности и взаимосвязанности. Таким образом, владелец начинает мешать компании, принимая неэффективные решения и занижая потенциальные темпы роста.

В итоге, если собственник продолжает работать вплоть до точки $E$, то можно считать, что его работа в течение всего этого времени не принесла вовсе никакой пользы компании, поскольку она могла бы достичь этой же точки $E$ без его участия. Если же владелец продолжает работать в компании и после точки достижения ею $E$, то он начинает уже непосредственно вредить и мешать росту бизнеса. В этом плане легко интерпретируемым показателем является $K$, , то есть предел стоимости компании, который может быть 
достигнут благодаря деятельности собственника.

Соответственно, одной из важнейших задач для владельца является определение того значения стоимости бизнеса, когда необходимо сформировать совет директоров и полностью или частично делегировать ему свои полномочия, не только исходя из собственной эффективности, но также принимая во внимание динамику развития самой компании (Кэтлин, Мэтьюз, 2008).

В связи с этим собственнику важно найти такую точку, где производные логистической и новой экспоненциальной кривой были бы равны. Таким образом, необходимо найти время to, которому соответствует точка на логистической кривой, оптимальная для ухода владельца из бизнеса.

Аналитическая задача, которую необходимо решить, чтобы найти такое время to, в котором производные логистической и новой экспоненциальной функций были бы равны, будет выглядеть следующим образом:

$$
\left[\frac{K^{\prime *} K_{0} * e^{R_{n} * t}}{K^{\prime}+K_{0} *\left(e^{R_{n}{ }^{*} t}-1\right)}\right]^{\prime}=\left[K_{1} * e^{\operatorname{Re}^{*}\left(t-t_{0}\right)}\right]
$$

при условии, что

$$
K_{1}=\frac{K^{\prime *} K_{0} * e^{R_{n}{ }^{*} t_{0}}}{K^{\prime}+K_{0} *\left(e^{R_{n}{ }^{*} t_{0}}-1\right)},
$$

т.е. это капитал на момент выхода собственника из бизнеса,

где

to - это время,соответствующее точке выхода собственника из бизнеса,

[...]' - в квадратных скобках стоят производные соответствующих функций.

Взяв соответствующие производные, а также подставив под $t$ переменную $t o$, которой соответствует точка ухода собственника из бизнеса, получим следующее выражение:

$$
\frac{\left(K^{\prime}-K_{0}\right) *\left(R_{n}-\mathrm{Re}\right)}{K_{0} * \operatorname{Re}}=e^{R_{n}^{*} t_{0}}
$$

Тогда

$$
t_{0}=\frac{1}{R_{n}} * \operatorname{Ln}\left[\frac{\left(K^{\prime}-K_{0}\right) *\left(R_{n}-\mathrm{Re}\right)}{K_{0} * \mathrm{Re}}\right]
$$

Таким образом, найдено то критическое значение to, после которого собственнику выгодно делегировать свои полномочия наемному органу управления и отойти от управления, став пассивным владельцем. На графике 5 точка to и соответствующая ей точка $G$ будут выглядеть следующим образом (см. рис. 2). 


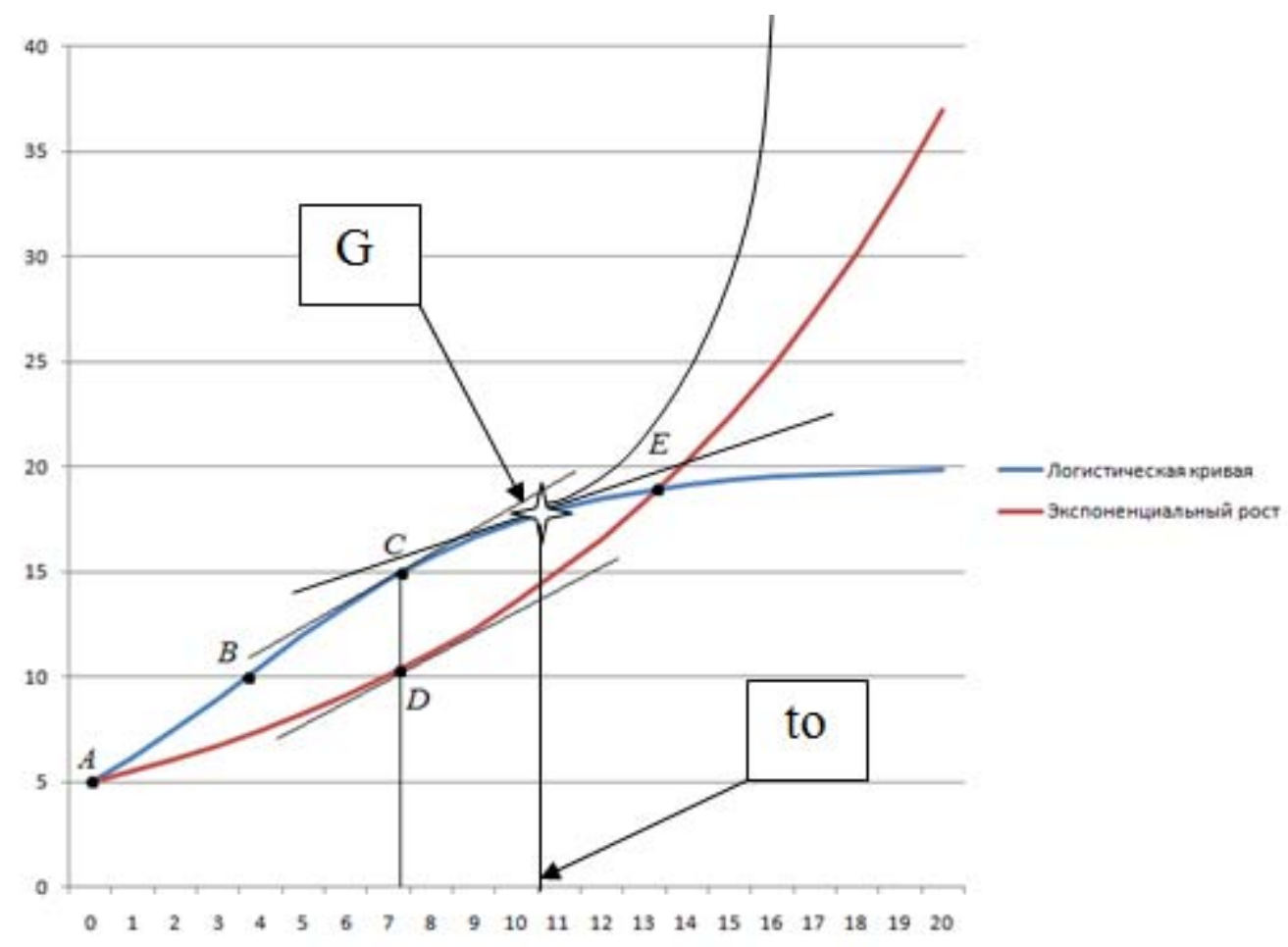

Рисунок 2. Оптимальная точка отхода собственника от управления

В соответствии с предпосылками модели, когда собственник уходит из бизнеса, логистическая кривая переходит в экспоненциальную. Данная кривая является аналогом кривой роста компании с пассивным собственником за одним исключением - базовым капиталом для этой новой экспоненциальной кривой будет являться та капитализация, которую сумел обеспечить собственник своей работой, т.е. стоимость собственного капитала компании (при допущениях, принятых в данной работе). В связи с тем что именно в точке $G$ производные логистической и новой экспоненциальной кривой равны, в том случае, если собственник уйдет из бизнеса чуть раньше или чуть позже, новая экспоненциальная кривая пройдет правее и ниже экспоненты, выходящей из точки $G$. Следовательно, стоимость компании, растущей по экспоненте начиная с точки $G$ в любой момент времени $t$ будет выше, нежели стоимость компании, растущей также по экспоненте, но выходящей из любой другой точки на логистической кривой.

Фактически точка $G$ является тем переломным моментом, когда собственнику выгоднее всего уйти из бизнеса - таким образом он обеспечит максимальный рост своего капитала. До точки $G$ (to) он управляет своим капиталом через управление компанией, т.е. как предприниматель, а после этой точки - управляет своим капиталом непосредственно, т.е. как капиталист.

\section{Заключение}

Таким образом, в рамках данной работы была разработана модель оценки эффективности деятельности собственника, позволяющая оценить динамику его эффективности на определенном отрезке времени и служащая индикатором целесообразности и выгоды его участия в управлении компанией. Основным новым параметром, оцененным в рамках модели, является суммарная стоимость времени, инвестируемого владельцем в бизнес $(S n)$. Следует отметить, что модель оценивает лишь один из критериев, на основе которого собственник имеет возможность принять решение о дальнейшем участии в бизнесе, игнорируя какие-либо другие мотивы и стимулы, которые могут повлиять на данное решение. Но авторы считают этот критерий важнейшим среди экономических критериев. 
На основании данного показателя измеряется фактическая результативность собственника за период (Sn), а также его эффективность $(S n / T n$, где $T n$ - количество часов работы собственника за период $n$ ). Измерение данного показателя с определенной периодичностью позволит владельцу увидеть динамику собственной эффективности, а также прогнозировать и корректировать время, инвестируемое им в бизнес (или, если точнее, на управление компанией). Одним из важнейших выводов и следствий из данной модели является неизбежная тенденция увеличения стоимости часа работы собственника по мере развития компании. Данный вывод абсолютно соответствует реальной практике: чем больше бизнес, тем выше стоимость времени работы его владельцев.

Была также разработана дополнительная модель, которая определяет связь между динамикой эффективности собственника и изменением стоимости компании во времени. Показана различная динамика изменения стоимости компании в зависимости от характера деятельности собственника - активного управленца или пассивного владельца. В то время как основная модель служит индикатором изменения эффективности собственника, дополнительная модель позволяет оценить экономические признаки и момент времени, когда ему выгоднее всего полностью отойти от оперативного управления компанией, принимая во внимание как его собственную эффективность, так и максимизацию стоимости компании во времени.

Следует отметить новизну подхода и модели, представленных в данной работе, как в отношении интерпретации ряда терминов, так и в ракурсе объяснения поведения владельцев в различных ситуациях. В рамках предпосылок модели четко определены причины ухода собственников из бизнеса в расцвете сил, что так часто происходит на практике. Если прежние модели рационального поведения собственника объясняли данную тенденцию его усталостью, нежеланием работать в компании или какими-либо внешними факторами, то новая модель не только объясняет причину, но и обосновывает рациональность таких решений. Показано, что максимизация абсолютного прироста личного состояния через увеличение прибыльности компании не является единственной рациональной экономической целью владельца. Альтернативной целью или ограничивающим условием может быть достижение максимума или определенного уровня его эффективности даже в ущерб абсолютному приросту капитала.

Модель имеет широкий спектр перспектив развития, таких как:

1. Изучение оптимального поведения собственника, уменьшающего свою долю акций от мажоритарной до миноритарной, и динамики его стимулов участия в управлении бизнесом.

2. Изучение поведения собственника, выступающего с позиции бизнес-ангела, а также причин и условий его невмешательства в управление компанией.

3. Изучение стимулов участия в управлении и владении долей бизнеса предпринимателя венчурной компании, ищущего бизнес-ангела.

Безусловно, выше перечислены лишь некоторые примеры потенциальных перспектив развития модели. В реальности возможностей для дальнейшего исследования может быть намного больше, ввиду научной новизны как самой модели, так и подхода к ее разработке.

\section{Список литературы}

1. Адизес И. Управление жизненным циклом корпорации. СПб.: Питер, 2008.

2. Бондаренко Н. К вопросу об эффективном собственнике // Политическая экспертная сеть «Кремль.org», 2009. URL: http://www.kreml.org/opinions/208314699.

3. Википедия [Электронный ресурс]. URL: http://ru.wikipedia.org/wiki/CAPM; http://ru.wikipedia.org/wiki/Логистическое_уравнение.

4. Гайдар Е. О состоянии российской экономики и возможных путях выхода из кризиса // Радио Свобода, $2009 . \quad$ URL: http://www.svobodanews.ru/content/transcript/1517060.html. 
5. Королев В. Об эффективном собственнике (тезисы с методологическим послесловием) // Корпоративный менеджмент, 2003. URL: http://www.cfin.ru/management/ practice/alt2003-2/16.shtml.

6. Лоскутов В. О собственности и эффективных собственниках // Российская Федерация сегодня, 2010. URL: http://www.russia-today.ru/tema-nomera/201-vladislav-loskutov-osobstvennosti-i-yeffektivnyx-sobstvennikax.html.

7. Королев В. Об эффективности и «крутости» собственников // Имущественные отношения в РФ. 2004. № 7.

8. Королев В. Корпоративное управление для наследников бизнеса: перспективное становится актуальным // Инициативы 21 века. 2011. № 4, 5.

9. Корпоративное управление / Пер. с англ. М.: Альпина Бизнес Букс, 2007.

10. Корпоративное управление и работа совета директоров в российских компаниях / под ред. А.А. Филатова и К.А. Кравченко. М.: Альпина Бизнес Букс, 2008.

11. Кросби А. Наследование бизнеса. СПб: Питер, 2004.

12. Кэтлин К., Мэтьюз Д. Путь собственника: от предпринимателя до председателя совета директоров / Пер с англ. 2-е изд. М.: Манн, Иванов и Фербер, 2008.

13. Лебланк Р., Гиллес Д. Совет директоров - взгляд изнутри / Пер с англ. М.: Альпина Бизнес Букс, 2006.

14. Материалы и презентации Ассоциации независимых директоров [Электронный pecypc]. URL: www.nand.ru.

15. Основы теории и методологии инноватики [Электронный pecypc]. URL: http://www.ii.spb.ru/material/methodical_m/m_1/Methodical_\&_manuals_1_1.pdf.

16. Понятковский Р. Эффективные собственники // Севастопольский корреспондент, 2011. URL: http://pulsev.com.ua/korrespondent/item/1583-effect2011.

17. Пособие по корпоративному управлению. В 6 т. М.: Альпина Бизнес Букс, 2004.

18. Российская корпорация: внутренняя организация, внешние взаимодействия, перспективы развития / под ред. Т.Г. Долгопятовой, И. Ивасаки, А.А. Яковлева. М.: Изд. дом ГУ ВШЭ, 2007.

19. Рыбаков М. Как навести порядок в своем бизнесе. Практикум. М.: ИКАР, 2011.

20. Современный экономический словарь [Электронный pecypc]. URL: http://slovari.yandex.ru/dict/economic/article/ses3/ses7941.htm?text=\%D1\%8D\%D1\%84\% D1\%84\%D0\%B5\%D0\%BA\%D1\%82\%D0\%B8\%D0\%B2\%D0\%BD\%D0\%BE\%D1\%81\% $\mathrm{D} 1 \% 82 \% \mathrm{D} 1 \% 8 \mathrm{C} \&$ stpar3=1.4.

21. Собственник и менеджер: строим эффективный бизнес / под ред. А.А. Филатова и К.А. Кравченко. М.: Альпина Бизнес Букс, 2008. 